\title{
Ecological urban design through Material and Energy Flow Analysis and Life Cycle Assessment: from an architect's perspective
}

\author{
Z. C. $\mathrm{Cai}^{1,2}$ \& R. Wennerstern ${ }^{2}$ \\ ${ }^{1}$ School of Architecture, Southeast University (SEU), China \\ ${ }^{2}$ Department of Industrial Ecology, Royal Institute of Technology (KTH), \\ Sweden
}

\begin{abstract}
The process of ecological urban design was studied through the perspective of Material/Energy Flow Analysis from an architect's viewpoint. The study examined how to control and adjust the production, transportation, distribution and consumption of material and energy flows in built environment systems, and how to analyse the relevant ecological design methods. Two environmental methods were used, Material/Energy Flow Analysis as the main method and Life Cycle Assessment as a parallel method, to analyse the 'integrated efficiency' of material and energy utilisation in the built environment and its significance for sustainable design. The analysis was applied to two cases: Material Flow Analysis of household wastewater treatment and Energy Flow Analysis of energy for heating and cooling buildings.
\end{abstract}

Keywords: Ecological Design, built environment, Material/Energy Flow Analysis, Life Cycle Assessment.

\section{Introduction}

Urban development is a complex process involving multiple stakeholders, e.g. government, developers, engineers, contractors, residents, etc., and different physical flows, e.g. water, solid waste, energy, foods, etc. The development also covers a long time span including construction, operation and demolition. Nowadays decisions regarding urban development are becoming increasingly complex because decision-makers have to consider social, economic and of course environmental aspects. 
The concept of Ecological Design has been defined as “...any form of design that minimizes environmentally destructive impacts by integrating itself with living processes" [1]. Thus, ecological urban design tries to minimise the impacts of the built environment on natural systems and to maintain harmony between the human environment and nature. This latter objective consists of two parts, i.e. that while maintaining a certain standard of living, urban development should minimise its inputs of natural resources and energy from the exterior and its outputs of pollutants to nature. From the perspective of Material and Energy Flow Analysis (M/EFA), ecological urban design involves adjusting and influencing the production, transportation, distribution and consumption of material and energy flows through forms of land use planning and physical space design in which the natural and built environments are integrated and human impacts on nature are minimised.

Conventionally architects have concentrated on functionality and aesthetics in architecture and urbanisation, while neglecting materials and energy consumption behind the physical forms. They have therefore contributed little to the sustainability of the contemporary built environment. In view of the complexity of urban development, decision-making methods are necessary as an analytical tool for architects to choose the most sustainable solutions.

The ecological design of a particular urban project reflects holistic thinking on material and energy flows. This approach involves examining the wider environmental impact on both a temporal and spatial scale. In the temporal perspective, the formerly used static environmental impact assessment should be replaced by a life cycle assessment covering raw material extraction, transportation, construction, operation and maintenance, renovation and demolition. In the spatial perspective, the emphasis should be expanded from project level to higher levels, e.g. urban, regional, national and even global. Therefore, ecological urban design through M/EFA should have the global biosphere in mind and trace all relevant flows in order to solve problems on the appropriate local levels. This involves thinking globally and acting locally.

\section{Material and Energy Flow Analysis and Life Cycle Assessment}

There are two environmental analytical tools that can be used for ecological urban design through M/EFA: Material/Energy Flow Analysis and Life Cycle Assessment.

The aim of the Material/Energy Flow Analysis is to specify and quantify the pathways of materials/energy into, through and out of specified system boundaries. This system can be on national, regional, community, company or even household scale. In general, material/energy flows in society are determined in a quantified manner. The entire circular flow of materials/energy is considered from the extraction of resources through processing and manufacture, use and recycling of the materials/energy to the point of final disposal. The capacity of the environment to absorb the pollutants and emissions produced is also taken into consideration. There are two main approaches in M/EFA: analysis of the 
flows of bulk materials (MFA) and analysis of flows of a single substance or a group of substances (SFA). M/EFA can be employed to analyse the environmental impact on a spatial dimension.

$\mathrm{M} / \mathrm{EFA}$ can be used to:

- $\quad$ Determine the major flows and stocks

- Predict future problems at an early stage

- Trace the fate of inflows

- Link specific pollution problems to their origin in society

- Assess the consequences of management changes on environmental flows and stocks.

Life Cycle Assessment (LCA) is a tool for analysing the life cycle of a product, service or project by evaluating its different flows (material and energy) and its environmental impacts throughout its lifespan. It is often described as a 'cradle-to-grave' tool, which means analysis of the materials used in making a product or service from extraction of materials and energy through to the return of the materials to the earth. LCA is also important for technology choices or process analysis.

A full LCA consists of four main phases (part of the ISO 14000 environmental management standards) [2]:

- Goal and scope: Definition of the system boundaries and description of the method/s applied for assessing potential environmental impacts

- Life Cycle Inventory (LCI): Collection of data (for inputs and outputs for all unit processes affected) and system modelling

- Life Cycle Impact Assessment: Evaluation of the potential environmental impacts from the emissions (global warming, acidification etc.), often referred to as Life Cycle Impact Assessment (LCIA) because it is based on the LCI results

- Interpretation: Establishment of conclusions. This phase is the most important one since it indicates whether the ambitions from the Goal and scope phase can be met.

Life Cycle Assessment helps to establish systematic thinking in order to analyse the whole life of an environmental issue, so that and 'out of sight, out of mind' and 'problem shifting' responses can be prevented. It also helps to trace the environmental burdens to the original sources. LCA is a comprehensively used quantitative method, and can be employed to analyse environmental impact in a temporal dimension.

In general, M/EFA and LCA are used in a quantitative way to evaluate all relevant environmental impacts. However, in the present study they were used as qualitative tools that could help architects and urban designers i) understand the broader process of material and energy flows and ii) establish a Life Cycle Perspective to analyse different stages of the life cycle of ecological urban design. Considering architects' background and the nature of their work, they are unlikely to carry out the scientific and quantitative research themselves, but implement and combine the results produced into physical forms through design. 
Architects and urban designers work as a bridge between research and realistic construction and thus a qualitative approach is more useful and feasible for these professionals.

\section{Ecological urban design through M/EFA and LCA}

\subsection{Integrated Efficiency (Ei)}

When M/EFA and LCA are applied to an urban project, the spatial level chosen is a key factor influencing the results. Different levels have different issues and measurements. The global built environment can be divided into eight levels: global, sub-continental, regional, city, urban district, neighbourhood, building cluster, and single building. Of these, architects and urban designers deal with

Table 1: $\quad$ Physical spatial levels and environmental issues.

\begin{tabular}{|c|c|}
\hline Global & Climate change \\
\hline Sub-continental & $\begin{array}{l}\text { Energy and resources } \\
\text { Environmental protection }\end{array}$ \\
\hline Regional & $\begin{array}{l}\text { Bio-diversity } \\
\text { Landscape ecology }\end{array}$ \\
\hline \multirow[t]{4}{*}{ City \& Urban District } & Bio-climatic planning \\
\hline & $\begin{array}{l}\text { Integration of land use and urban } \\
\text { transportation: TOD model }\end{array}$ \\
\hline & $\begin{array}{l}\text { External resources and energy supply: } \\
\text { Material/Energy Flow Analysis }\end{array}$ \\
\hline & Div- \\
\hline \multirow[t]{4}{*}{ Urban Neighbourhood } & Local natural resources \\
\hline & $\begin{array}{l}\text { Urban density: FAR analysis, effective and } \\
\text { mixed land use }\end{array}$ \\
\hline & $\begin{array}{l}\text { Waste treatment: Source separation, recycling, } \\
\text { reuse }\end{array}$ \\
\hline & $\begin{array}{l}\text { Local agricultural development and greenland } \\
\text { planning }\end{array}$ \\
\hline $\begin{array}{l}\text { Building Cluster } \\
\text { \& Single Building }\end{array}$ & $\begin{array}{l}\text { High comfort, low energy, low emission, reuse } \\
\text { Material/Energy Flow Analysis }\end{array}$ \\
\hline
\end{tabular}


projects from the level of single building to the level of city. Table 1 shows interlinks between different physical boundary levels and related environmental issues. Material and energy flows, as basic issues of ecological design, proceed from the very beginning (nature) through all the relevant levels and back to the very beginning (nature) again.

For a certain urban project, energy flows may include electricity, heating, cooling, mechanical, etc., while material flows may include water, fuel, building materials, agricultural products, industrial products, sewage, solid waste, greenhouse gases, etc. In a more general sense, human movements can also be regarded as a material flow, so urban transportation can be analysed by M/EFA.

At the urban level, the flows of materials and energy can be divided into four stages: external supply or local production, transportation, distribution, consumption (Figure 1). After these four stages, part of materials and energy can be recycled or reused, while others become environmental burdens that need to be absorbed naturally or treated artificially. Moreover, some flows will be accumulated as different types of pollution. However, each stage has different possibilities to reduce environmental impacts (Figure 1). The chart presented in Figure 1 varies slightly when used to indicate specific flows.

One of the main objectives of ecological urban design is to utilise materials and energy with a high efficiency, which means achieving more services with less material and energy consumption. Integrated Efficiency considering all stages of material and energy flows is essential to ecological design.

Integrated Efficiency (Ei) consists of:

1) Production Efficiency (Ep): Ep shows the efficiency of producing a certain material or energy. In terms of ecological urban design, it means how the urban project obtains its supply of materials and energy. For instance, electricity can be obtained directly from the national grid or produced by a local facility such as PV panels or local power generator. The goal of ecological design is to maximise the use of renewable materials and energy.

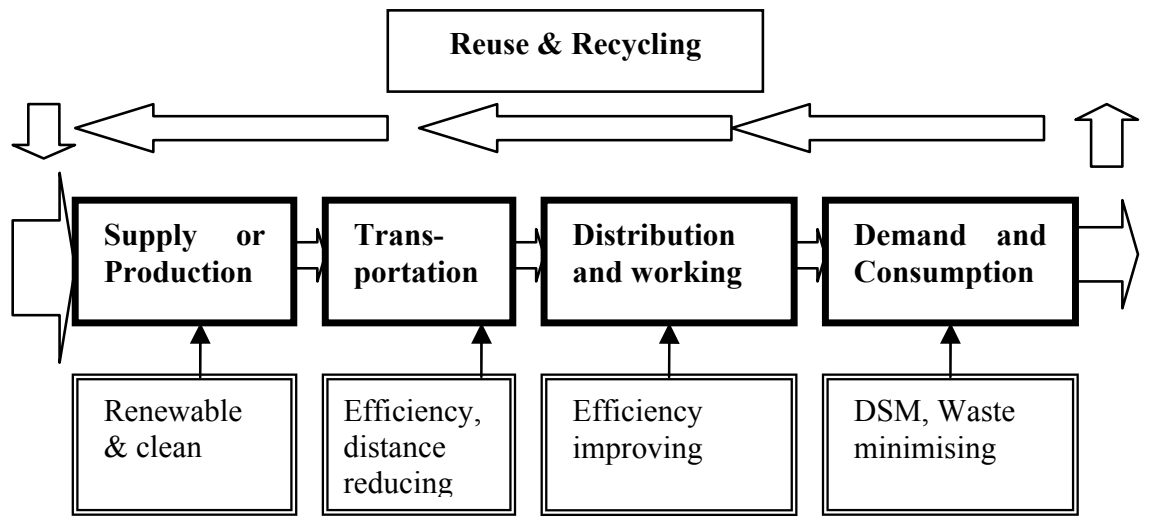

Figure 1: $\quad$ Conceptual model of $\mathrm{M} / \mathrm{EFA}$ in an urban area. 
2) Transportation Efficiency (Et): Et shows the efficiency during the transportation of a certain material and energy flow from production point to target point. Thus it shows how much extra materials and energy are used to support certain flows and how much of the flows is lost during transportation. Improving Et includes reducing transportation distance and decreasing avoidable losses.

3) Working Efficiency (Ew): Ew indicates the efficiency of certain material and energy flows to fulfil a specific service requested by human needs. This stage is very important for ecological design. Type of equipment or working system can have a major effect on working efficiency.

4) Saving Efficiency (Es): Es is connected with life style and standard of living. It means the material and energy saved because of environmental awareness leading to a change in life style, and sometimes because of improved design leading to lower demand. Es shows the high potential of people's subjective attitude towards environmental protection and the great potential of good design.

From a holistic point of view, the Integrated Efficiency (Ei) of a system is the combined effect of these four Efficiencies, which can be expressed conceptually as follows:

$$
f(\boldsymbol{E} \boldsymbol{i})=\boldsymbol{E p} \times \boldsymbol{E} \boldsymbol{t} \times \boldsymbol{E} \boldsymbol{w} \times \boldsymbol{E s}
$$

This conceptual equation means the four stages in material and energy flows should be considered holistically, without focusing too much on one stage or another, because the overall efficiency of a system may be low in spite of high efficiency in a certain stage. More problematically, the four Efficiencies often contradict each other, so focusing too much on one stage could even harm the other stages. Therefore, the Integrated Efficiency controls the whole process of material and energy flows within a certain spatial boundary.

The concept of Integrated Efficiency is explained in detail in the following section using two examples: Material Flow Analysis (MFA) of household wastewater treatment; and Energy Flow Analysis (EFA) of energy for heating and cooling buildings.

\subsection{Case study}

\subsubsection{Material Flow Analysis of the household wastewater treatment process}

The Material Flows in household wastewater treatment comprise a four-stage process of wastewater being generated in houses, running through pipes, being treated and finally being recycled or returned to the natural environment (Figure 2).

1) Wastewater generation

Wastewater is generated by daily activities such as cooking, flushing toilets, bathing and laundry. Wastewater consumption can be decreased by reducing 


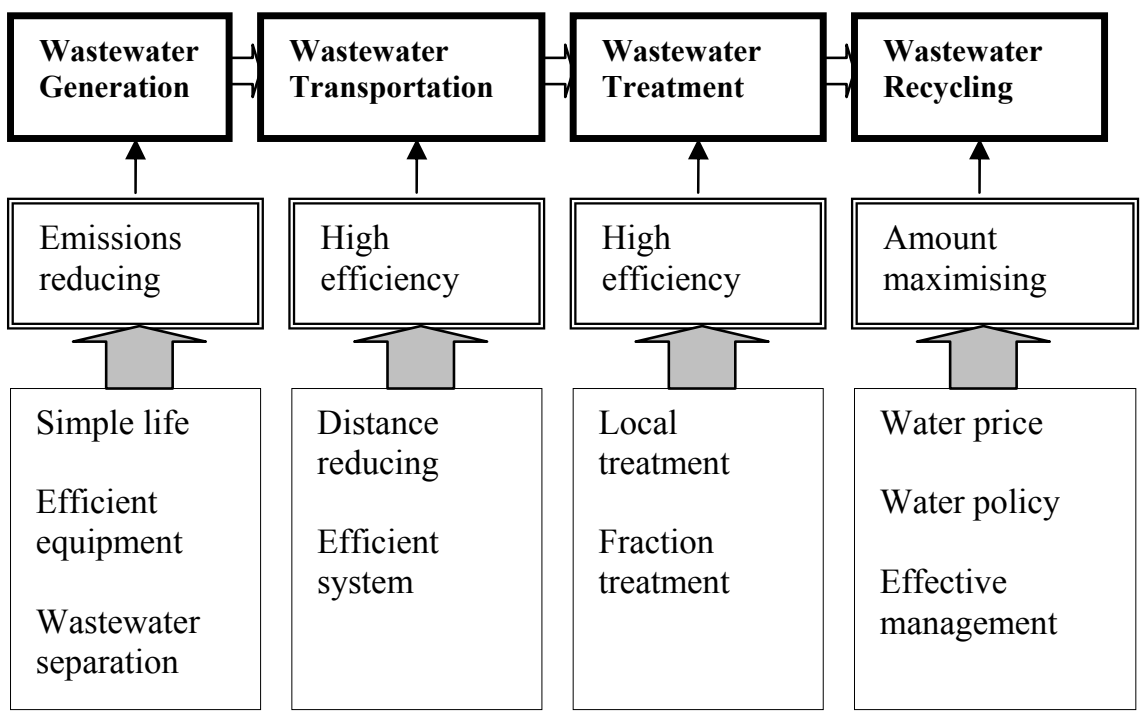

Figure 2: Conceptual model of MFA of household wastewater.

unnecessary use and by using water-efficient equipment. Applying MFA with a holistic view, wastewater separation at source is important in ecological design to avoid different kinds of wastewater being mixed and then having to be separated again in the wastewater treatment plant.

2) Wastewater transportation

The modern sewage system based on the flushing toilet was invented in Europe in the $19^{\text {th }}$ century. It has played a major role in preventing the spread of diseases and in reducing pollution, but the obvious drawback is that it needs huge amounts of tap water. Furthermore, all kinds of wastewater are mixed and transported to the municipal wastewater treatment plant via the sewer system. Wastewater crosses different physical levels, including building, building cluster, neighbourhood and urban district. With the expansion of urban boundary, it costs more to build all the necessary plants and install sewage infrastructure. Wastewater separation at source and local treatment could reduce all costs substantially.

\section{3) Wastewater treatment}

The nutrients in the conventional wastewater treatment system are difficult to remove or recycle to farmland and cause eutrophication problems in receiving waters. On the other hand, agricultural land is lacking in these same nutrients and has to rely heavily on chemical fertilisers, the manufacture of which is highly energy-intensive. 
4) Wastewater recycling

It is often forgotten that urban wastewater is an important and reliable water resource. After simple treatment, the majority of source-separated wastewater could be reused for industrial purposes, watering vegetation, washing urban streets, etc.

\section{Discussion}

The qualitative MFA of household wastewater and possible ecological design methods during different stages to reduce environmental impacts are shown in Figure 2. Reducing wastewater at source is key to the whole system. Wastewater separation at source is essential to decrease the total cost of wastewater treatment, because the initial cost of building source-separation facilities will be easily repaid by the huge savings made. Most of the wastewater generated from cooking, bathing and laundry could be treated locally to reduce the cost of transportation, although the efficiency of local, small-scale treatment plants is lower than that of urban, large-scale plants. Therefore, holistic thinking should be employed and the Integrated Efficiency should be considered as the deciding factor.

\subsubsection{Energy Flow Analysis (EFA) of energy for heating and cooling buildings}

The Energy Flow of energy for heating and cooling buildings comprises the four-stage process of energy being produced and supplied from the exterior of a certain physical boundary or produced locally, being transported through several spatial levels, being distributed to buildings and working by being transformed into heating and cooling to provide an expected indoor thermal comfort demanded by modern life.

\section{1) Energy production}

Essentially, all energy on earth derives from the sun. Fossil fuels such as oil and coal originate from the solar energy accumulated millions of years ago. They are non-renewable in terms of the short human lifespan. To minimise the impacts of a building, renewable energy types such as solar, wind, geothermal, hydraulic, etc. should be used to replace fossil fuels as much as possible.

\section{2) Energy transportation}

Energy transportation indicates how the primary energy obtained from nature is transformed and transported to buildings. Fossil fuels normally cannot be used directly for heating and cooling, but the energy embodied in them is easy to transform into electricity or thermal energy and to transmit through different spatial boundaries. Renewable energy types such as solar energy and geothermal energy are low value exergy that needs special technology in order to be utilised for heating and cooling and are difficult to transport over long distances. 


\section{3) Energy distribution and work}

Energy supplied to the outside of buildings needs specialist equipment to work as heating and cooling. There are two ways to distribute heating and cooling: convection or radiation via steam or water. The efficiency of ceiling (or floor) cooling and heating by radiation is generally higher than that of radiators operating mainly by convection. Furthermore, it is easy to utilise low value exergy in ceiling (or floor) cooling and heating.

\section{4) Energy demand}

Total energy demand includes direct energy demand for consumption and indirect energy losses from buildings. Therefore, there are two approaches to decrease energy demand:

Direct energy demand can be decreased by good designs, such as exterior sun screens in hot regions to decrease the cooling load, bio-climatic designs to set the orientation and openings of buildings, etc. Another measure is to tolerate a more reasonable indoor temperature, such as a higher temperature in summer and a lower temperature in winter. However, this measurement is related to life style and people's expectations of comfort.

Indirect energy loss can be decreased by improving building envelopes through better thermal insulation, air-tight windows, reducing the area of glass in cold regions, etc.

\section{Discussion}

From raw fossil fuels to the final heating and cooling utilised in buildings, there can be different stages that pass through different spatial levels (Figure 3). For the objective of ecological design to save energy and materials holistically, all stages have to be considered equally. Any approach that focuses on the efficiency in one stage while neglecting others may result in harm to the whole system. For example, some 'hi-tech' buildings use a range of complicated and delicate equipment to reduce direct energy consumption and are declared energyefficient. However if the energy and resources consumed by the production of this equipment and its maintenance are taken into account using a life cycle perspective, the 'hi-tech' buildings may turn out to be more energy-consuming than their 'low-tech' counterparts.

An example from this area confirms the importance of Integrated Efficiency. Heating and cooling produced by geothermal heat pumps (GHP) comes from renewable energy. Moreover, GHP are more efficient than conventional boilers. However, the low temperature heating by GHP cannot be transported over a long distance, so it applies to levels lower than the urban neighbourhood level. In contrast, high temperature heating by boilers can be transported over long distances by water or steam but uses large amounts of pipe work and thermal insulation, while there are also losses during the process. 


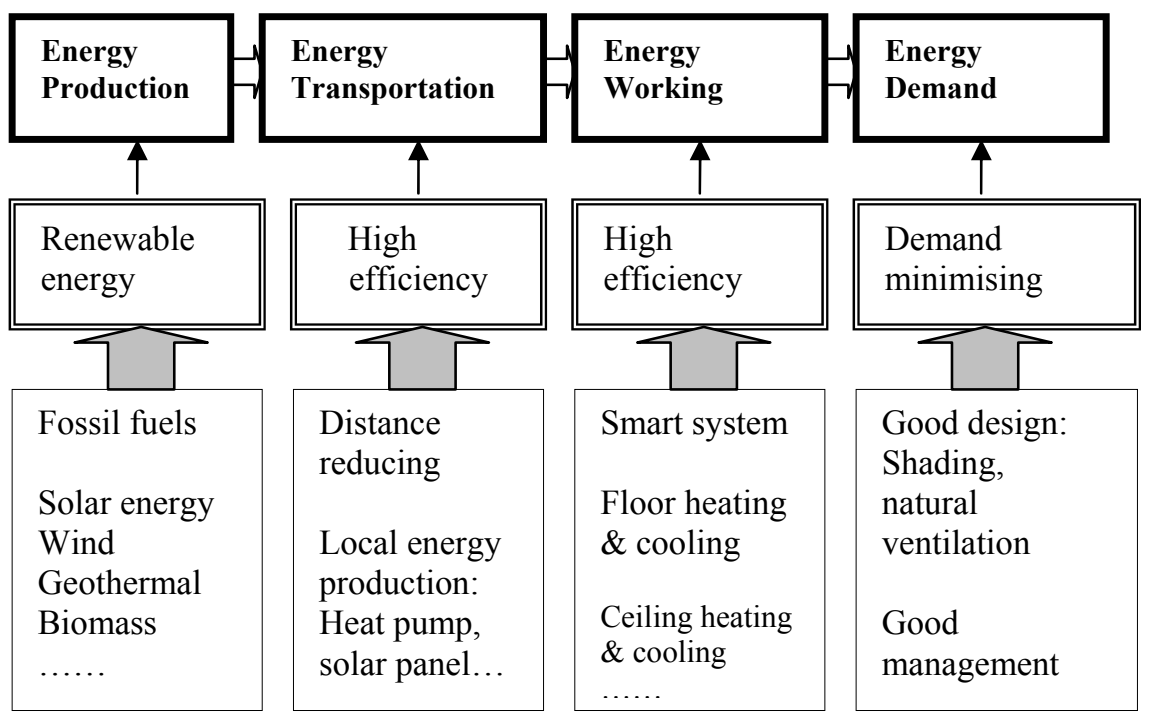

Figure 3: Conceptual model of EFA of energy for heating and cooling buildings

\section{Conclusion}

Due to the complexity and uncertainty of the built environment, conventional design methods with subjective and empirical analysis cannot effectively deal with environmental issues. Rational analysis becomes an indispensable step for ecological design, since otherwise the environmental objectives cannot be fully achieved through designing.

Systems thinking is crucial to ecological urban design. Different spatial levels in the built environment are interconnected and interactive. Different stages of material and energy flows are interwoven with spatial levels into an integral system that should be treated holistically without neglecting any stages or any levels.

Material/Energy Flow Analysis and Life Cycle Assessment are two widely used environmental systems analysis methods. They allow the impacts of certain design proposals to be evaluated from both a spatial and temporal perspective. Although it may be difficult for architects and urban designers to use the two methods quantitatively, they can be extremely helpful when used qualitatively to establish systems thinking that renders ecological urban design proposals realistic and effective.

\section{Acknowledgement}

This research was funded by National Natural Science Foundation of China. Project name: Transition and Redevelopment of Old Urban Industrial Areas in the Post-Industrial Period. Project number: 50878045. 


\section{References}

[1] Van der Ryn, S \& Cowan, S. 1996. Ecological Design. Washington D.C.: Island. 17-32.

[2] Nicoline Wrisberg, etc. editor. 2002 Analytical Tools for Environmental Design and Management in a Systems Perspective. Kluwer Academic Publishers. 45-46. 